\title{
PENGEMBANGAN MEDIA INFORMASI UNTUK EDUKASI PELAYANAN PENDAFTARAN PASIEN DI PUSKESMAS SUNYARAGI KOTA CIREBON
}

\author{
Mustara Mustara $^{1 *}$, Suhartini Suhartini ${ }^{1}$, Retno Hidayati ${ }^{1}$ \\ ${ }^{1}$ Prodi D3 Rekam Medik dan Informasi Kesehatan Cirebon, Poltekkes Kemenkes Tasikmalaya, Indonesia \\ *Email : taramustara@gmail.com
}

\begin{abstract}
One criteria of health center accreditation assessment is the availability of information about the flow of the service procedure when patients register at the registration counter. Clarity of information received by the patient will give satisfaction. The first impression at the registration counter will shape the patient's perception of the overall service at the health center. The purpose of this activity is to provide information media for educating patients when registering about the service flow and service procedure at the registration counter. The methods used were advocacy to the health center, identification and analysis of media information needs, information media creating, media trials, socialization, and evaluation. The results are the availability of information media in the form of animations, leaflets, and bannerabout the flow of service procedure at the health center.
\end{abstract}

Keywords: Media Development, Registration Procedure Flow, Sunyaragi Health Center

\begin{abstract}
ABSTRAK
Salah satu kriteria penilaian akreditasi puskesmas adalah tersedianya informasi tentang alur prosedur pelayanan saat pasien mendaftar di loket pendaftaran. Kejelasan informasi yang diterima pasien akan memberikan rasa puas terhadap pasien. Kesan pertama di loket pendaftaran akan membentuk persepsi pasien terhadap keseluruhan pelayanan di puskesmas. Tujuan kegiatan ini menyediakan media informasi untuk edukasi pasien saat mendaftar tentang alur dan prosedur pelayanan di loket pendaftaran. Metode yang lakukan adalah advokasi ke puskesmas, identifikasi dan analisis kebutuhan media informasi, perencangan media informasi, ujicoba media, sosialisasi, dan evaluasi. Hasil yang diperoleh tersedianya media informasi dalam bentuk animasi, leaflet, dan banner tentang alur prosedur pelayanan di puskesmas.
\end{abstract}

Kata Kunci: Pengembangan Media, Alur Prosedur Pendaftaran, Puskesmas Sunyaragi

\section{PENDAhuluan}

Puskesmas merupakan garda depan dalam penyelenggaraan upaya kesehatan dasar. Puskesmas dapat menjalankan fungsinya secara optimal harus dikelola secara optimal baik kinerja pelayanan, proses pelayanan, maupun sumber daya yang digunakan. Masyarakat menghendaki pelayanan kesehatan yang aman dan bermutu, serta dapat menjawab kebutuhan mereka, oleh karena itu upaya peningkatan mutu, manajemen risiko dan keselamatan pasien perlu diterapkan dalam pengelolaan Puskesmas. Untuk menjamin bahwa perbaikan mutu, peningkatan kinerja dan penerapan manajemen risiko dilaksanakan secara berkesinambungan di Puskesmas, maka perlu dilakukan penilaian oleh pihak eksternal dengan menggunakan 
standar yang ditetapkan yaitu melalui mekanisme akreditasi [1].

Prinsip dari pelayanan kesehatan yang bermutu adalah keberpihakan terhadap pelanggan. Dua hal yang perlu dipantau dalam upaya perbaikan mutu adalah kepuasan pelanggan dan standar pelayanan kesehatan yang harus dilakukan secara seimbang [2]. Puskesmas wajib menyediakan informasi tentang pelayanan kesehatan yang diberikan kepada masyarakat sebagai wujud dari hak akses masyarakat terhadap pelayanan kesehatan. Keselamatan pasien sudah harus diperhatikan sejak pertama pasien kontak dengan Puskesmas, dengan demikian prosedur pendaftaran sudah mencerminkan penerapan upaya keselamatan pasien, terutama dalam identifikasi pasien.

Pasien membutuhkan informasi yang jelas di tempat pendaftaran, oleh karena itu informasi pendaftaran harus tersedia dengan jelas yang dapat dengan mudah diakses dan dipahami oleh pasien. Pasien mempunyai hak untuk memperoleh informasi tentang tahapan pelayanan klinis yang akan dilalui mulai dari proses kajian sampai pemulangan. Informasi tentang tahapan pelayanan yang ada di Puskesmas perlu diinformasikan kepada pasien untuk menjamin kesinambungan pelayanan. Informasi tersebut termasuk apabila pasien perlu dirujuk ke fasilitas yang lebih tinggi dalam upaya menjamin kesinambungan pelayanan. Tahapan pelayanan klinis adalah tahapan pelayanan sejak mendaftar, diperiksa sampai dengan meninggalkan tempat pelayanan dan tindak lanjut di rumah jika diperlukan [1].

Menurut Kotler (1994), definisi kepuasan konsumen adalah tingkat perasaan seseorang setelah membandingkan kinerja/hasil yang dirasakan dibandingkan dengan harapannya. Jika persepsi konsumen terhadap suatu produk atau jasa melebihi apa yang diharapkan, tentu saja konsumen sangat puas, akan tetapi jika persepsi konsumen berada di bawah tingkat yang diharapkan, tentu saja konsumen tidak puas atau sangat kecewa [3].

Agar informasi tersampaikan dengan baik kepada sasaran diperlukan saluran berupa media yang tepat[4]. Salah satu media yang digunakan dalam proses pembelajaran dan diyakini dapat lebih menggairahkan adalah audio visual. Media audio visual adalah media penyampai informasi yang memiliki karakteristik audio (suara) dan visual (gambar). Jenis media ini memiliki kemampuan lebih baik karena memiliki karakteristik audio dan visual sekaligus [5].

Pedoman Penyelenggaraan Rekam Medis terdapat beberapa informasi penting yang harus ditangkap oleh petugas pendaftaran, antara lain: dokter penanggung jawab unit pelayanan, nomor pasien, alamat lengkap, tempat/tanggal lahir, umur, jenis kelamin, status keluarga, agama dan pekerjaan. Pentingnya informasi - informasi tersebut menjadi dasar utama pengumpulan data dan informasi pasien yang terpenting sebelum pelayanan dilaksanakan. Media sebagai salah satu upaya edukasi bagi pasien maupun keluarganya untuk memperoleh informasi serta tujuan dari lengkapnya data pasien[6].

\section{METODE}

Metode dalam pelaksanaan kegiatan ini berupa identifikasi dan diskusi melalui wawancara. Adapun tahapan kegiatan yang dilakukan antara lain:

1. Advokasi kepada pihak Puskesmas Sunyaragi. Sasaran dalam kegiatan ini adalah kepala puskesmas, petugas rekam medis dan petugas pada setiap unit pelayanan yang ada di Puskesmas Sunyaragi yaitu unit pemeriksaan umum, pelayanan KIA/KB dan pelayanan kesehatan gigi. Kegiatan ini ditujukan untuk mendapatkan dukungan dalam pelaksanaan kegiatan.

2. Identifikasi kebutuhan isi media informasi. Identifikasi kebutuhan isi media informasi alur dan prosedur pelayanan dilakukan dengan cara berdiskusi dengan pihak Puskesmas Sunyaragi. Diskusi tersebut antara lain membahas mengenai media informasi yang sudah tersedia dan belum tersedia di puskesmas. Identifikasi juga membahas tentang bentuk media informasi yang perlu dikembangkandan isi media informasi (materi) yang akan dituangkan dalam media informasi yang dikembangkan.

3. Analisis kebutuhan isi media informasi. Analisis kebutuhan isi media informasi ini dimaksudkan untuk membandingkan antara item-item hasil identifikasi yang sudah dilakukan di Puskesmas Sunyaragi dengan teori maupun regulasi yang ada. Setelah mendapatkan kesesuaian antara kebutuhan puskesmas dengan teori/regulasi, selanjutnya item-item tersebut ditindaklanjuti dalam pembuatan media informasi pelayanan pendaftaran pasien.

4. Merancang Media Informasi. Media informasi yang dirancang adalah dalam bentuk video animasi, leaflet dan banner tentang alur pelayanan perndaftaran pasien. 
5. Uji Coba. Media informasi yang sudah tersusun diujicoba pada pelayanan pendaftaran di Puskesmas Sunyaragi. Tahap uji coba ini dilakukan dengan melibatkan petugas puskesmas dan beberapa pasien yang berkunjung ke puskesmas. Beberapa masukan dari hasil ujicoba media menjadi bahan untuk tahap selanjutnya.

6. Sosialisasi. Media yang sudah tersusun dilakukan kepada seluruh petugas Puskesmas Sunyaragi. Setelah disepakati oleh seluruh petugas puskesmas, selanjutnya media hasil pengembangan disosialisasikan kepada pasien Puskesmas Sunyaragi.

7. Evaluasi. Media informasi yang sudah selesai dibuat ditayangkan pada saat pelayanan pendaftaran di Puskesmas Sunyaragi. Evaluasi dilakukan dengan cara diskusi dengan pihak Puskesmas Sunyaragi untuk mengevaluasi penayangan dan pemasangan media agar terintegrasi dalam program pelayanan pendaftaran. Selain itu evaluasi juga dilakukan dengan cara mewawancarai beberapa pasien yang berkunjung dan melihat media informasi dan tayangan animasi tersebut.

\section{HASIL DAN PEMBAHASAN}

Hasil dari kegiatan berupa tersedianya 3 (tiga) jenis media informasi untuk edukasi pasien dalam pelayanan pendaftaran berupa alur dan prosedur pelayanan di Puskesmas Sunyaragi. Sebagaimana dinyatakan dalam standar akreditasi puskesmas bahwa informasi tentang pelayanan wajib disediakan oleh puskesmas sebagai bentuk pemenuhan hak pasien mendapatkan informasi yang jelas dan akurat. Selain itu juga dalam presfektif mutu khususnya dimensi jaminan dinyatakan bahwa konsumen akan mempersepsikan rasa puas terhadap pelayanan apabila ada jaminan kejelasan apa yang akan dilalui dan didapatkan selama mendapat pelayanan di puskesmas.

Substansi dari media informasi yang dibuat adalah tentang alur pendaftaran pasien. Dalam media informasi tersebut digambarkan pertama kali adalah kondisi pasien apakah gawat darurat atau tidak. Apabila kondisi pasien gawat maka langsung menuju ruang tindakan, namun apabila kondisi pasien tidak gawat darurat maka pasien mengambil nomor urut. Untuk nomor urut dibedakan menjadi 2 (dua) apakah pasien umum atau pasien BPJS. Setelah pasien mendapatkan nomor antrian selanjutnya menunggu di ruang tunggu. Pasien dipanggil oleh petugas pendaftaran sesuai dengan nomor antrian.

Pada saat dipanggil oleh petugas, pasien akan ditanyakan (a) Apakah sudah pernah berobat atau belum di Puskesmas Sunyaragi (meminta Kartu Identitas Berobat); (b) Menunjukan kartu identitas diri; (c) Pasien ditanyaapakah memiliki kartu jeminan kesehatan; (d) Poliklinik yang dituju. Setelah itu petugas akan menyiapkan rekam medis sesuai dengan status pasien (baru atau lama), menulis identitas pasien kedalam sistem. Pasien selanjutnya menunggu di ruang tunggu poliklinik yang dituju. Pasien selanjutnya dipanggil menuju ruang pemeriksaan. Setelah mendapat pelayanan di poliklinik yang dituju ada beberapa kemungkinan terhadap pasien antara lain: (a) Pasien dirujuk ke fasilitas pelayanan kesehatan lanjutan; (b) Pasien mendapat konseling; (c) Pasien mendapat resep obat; (d) Pasien memerlukan pemeriksaan penunjang lanjutan. Adapun hasil dari pengembangan media informasi tersebut berupa banner yang berisi tentang alur pendaftaran pasien sebagaimana terlihat pada Gambar 1. 


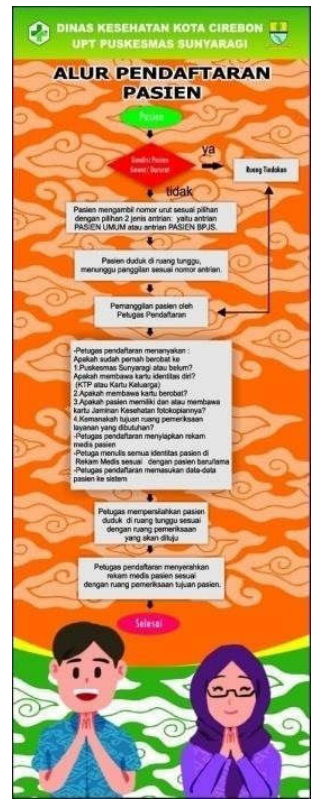

\section{Gambar 1 Banner Alur Pendaftaran Pasien}

Banner tersebut dipasang di pintu masuk Puskesmas Sunyaragi. Melalui informasi tersebut pasien sudah mendapatkan gambaran tahapan apa saja yang akan dialami pasien selama di puskesmas serta berkas apa saja yang harus disiapkan pasien untuk menunjang pelayanan di pendaftaran lebih cepat.

Informasi tentang alur dan prosedur pendaftaran dipaparkan lagi kepada pasien selama menunggu di ruang tunggu puskesmas melalui tayangan animasi. Video animasi dibuat dalam durasi 2 menit. Tujuan dari penayangan animasi ini adalah menguatkan informasi yang sudah didapatkan oleh pasien melalui media lain. Melalui media animasi (audio visual) pasien akan mendapat gambaran lebih jelas. Video animasi ditayangkan melalui televisi berukuran 32 inchi yang terpasang di ruang tunggu. Kontol terhadap tayangan di televisi tersebut dikendalikan oleh petugas pendaftaran. Beberapa potongan scene dalam video animasi tersebut terlihat pada gambar 2 . 


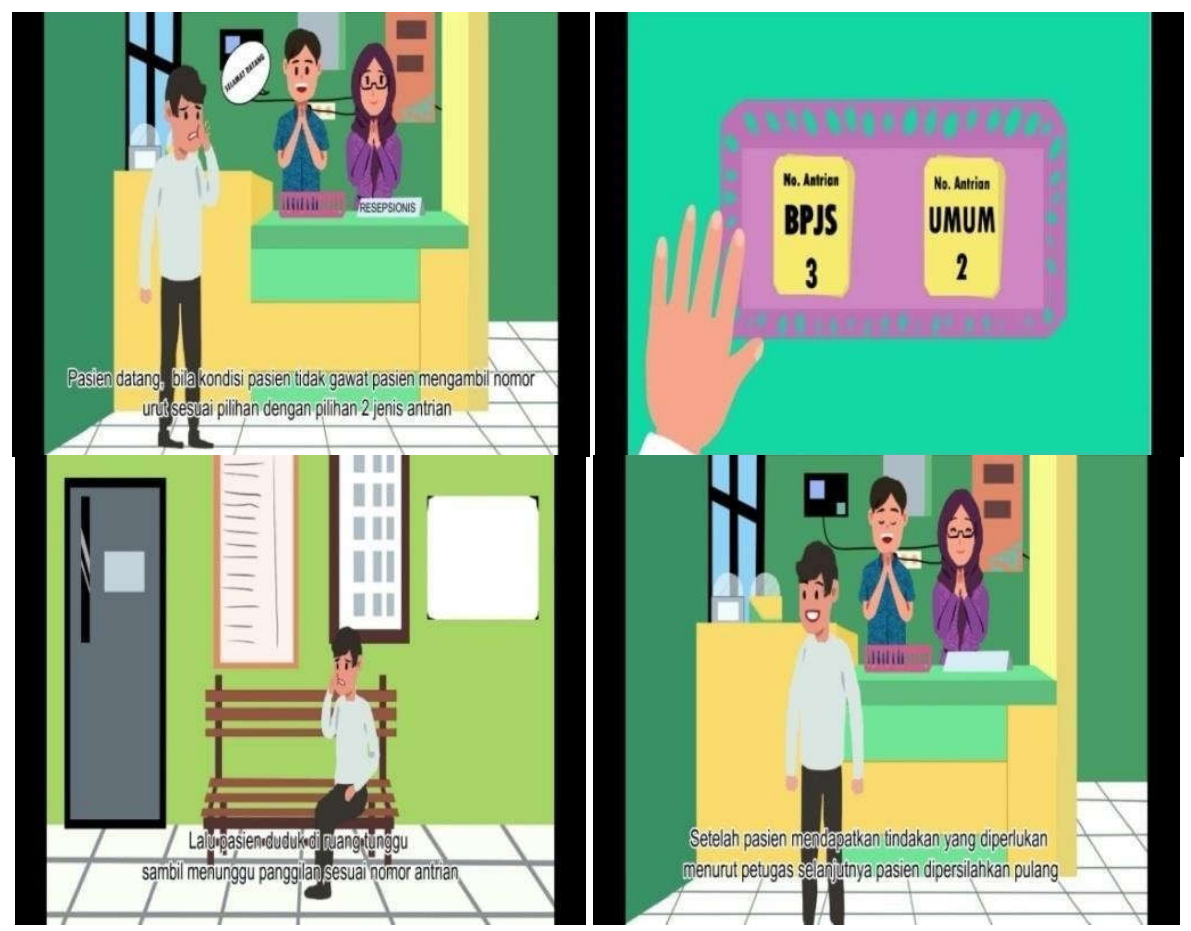

Gambar 2 Animasi Alur Pendaftaran Pasien

Jenis media informasi lain yang dikembangkan adalah leaflet. Leaflet yang dibuat terdiri dari 3 (tiga) buat, leaflet untuk di poliklinik umum, leaflet untuk di poliklinik KIA, dan leaflet untuk di poliklinik gigi. Masing - masing leaflet berisi tentang alur pemeriksaan di poliklinik tersebut serta informasi kesehatan/penyakit yang terkait dengan poliklinik tersebut. Leaflet di poliklinik umum informasi yang disusun adalah tentang penyakit inspeksi saluran pernafasan akut (ISPA), leaflet di poliklinik KIA informasi yang dibuat tentang jenis kontrasepsi, leaflet di poliklinik gigi berisi informasi tentang cara menjaga kesehatan gigi dan mulut. Leaflet yang dihasilkan sebagaimana terlihat pada gambar 3, 4, dan 5.

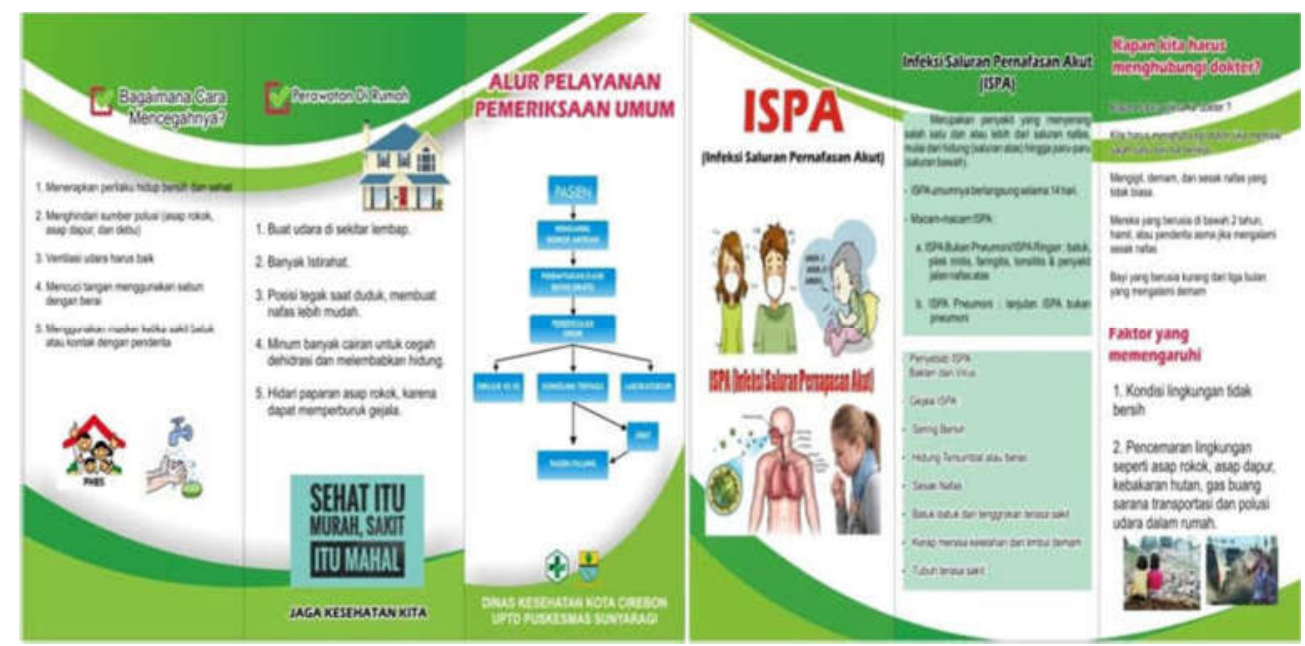

Gambar 3 Leaflet di Poliklinik Umum 


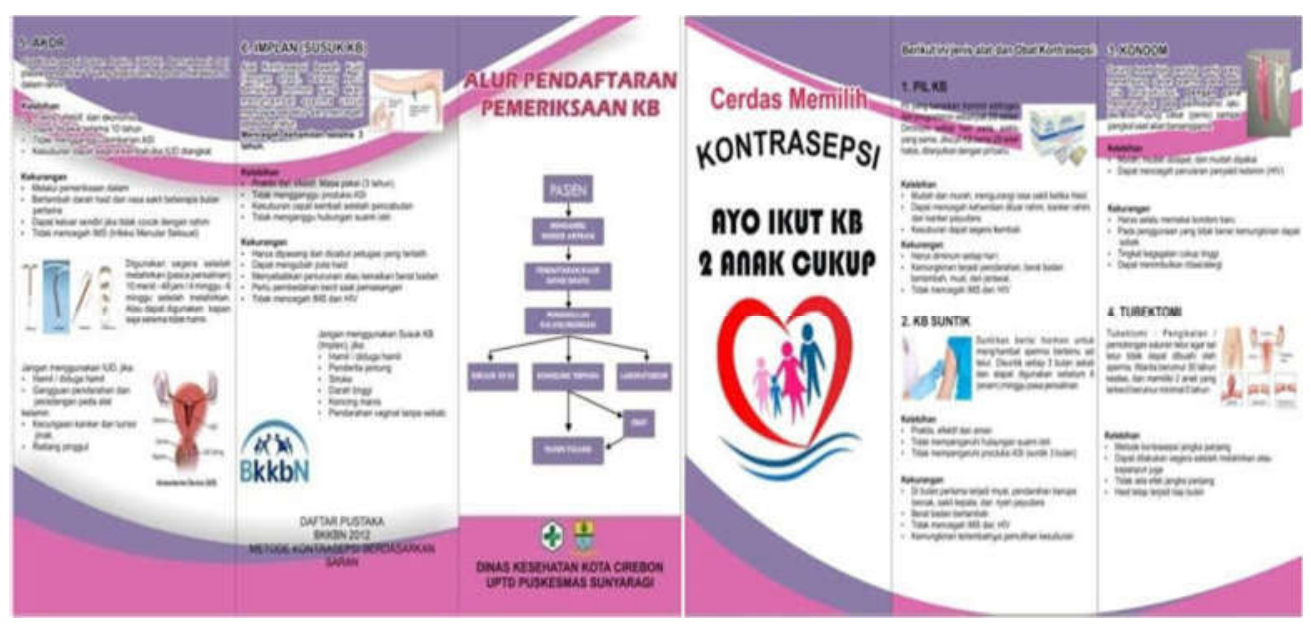

Gambar 4 Leaflet di Poliklinik KIA

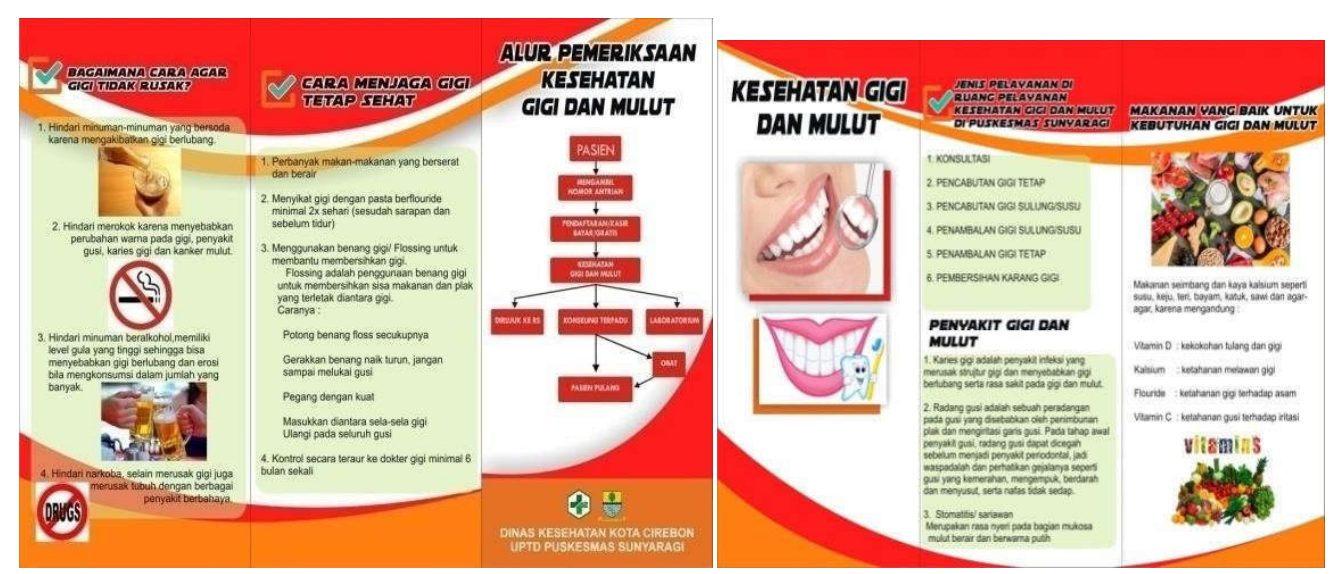

Gambar 5 Leaflet di Poliklinik Gigi

Leaflet yang disusun pada setiap poliklinik ditujukan selain untuk menguatkan informasi tentang alur pendaftaran dan pemeriksaan disetiap polikliniknya juga dimaksudkan untuk memberikan wawasan lain tentang hal - hal yang terkait dengan penyakit dan kesehatan secara umum. Bentuk leaflet disediakan di loket pendaftaran dan ruang poliklinik yang bersangkutan. Diharapkan leaflet selanjutnya dapat dibawa oleh pasien setelah mendapatkan seluruh pelayanan di puskesmas.

\section{SIMPULAN}

Persepsi pasien terhadap mutu pelayanan kesehatan di puskesmas dapat dimulai dari kesan yang diperolehnya pada saat pelayanan pendaftaran. Informasi yang jelas dan akurat yang disediakan akan membantu pasien mendapatkan pelayanan yang cepat khususnya di pendaftaran. Oleh karena itu pembuatan dan penayangan banner, animasi, dan leaflet tentang alur dan prosedur pendaftaran pasien dapat mendorong memahami apa yang akan dilaluinya dalam menerima pelayanan di puskesmas. 


\section{DAFTAR PUSTAKA}

[1] Kementerian Kesehatan RI, Peraturan Menteri Kesehatan Nomor 46 Tahun 2015 tentang Akreditasi Puskesmas, Klinik Pratama, Tempat Praktik Mandiri Dokter, dan Tempat Praktik Mandiri Dokter Gigi. Jakarta: Kemenkes RI, 2015.

[2] Rizanda Machmud, "Manajemen Mutu Pelayanan Kesehatan," Jurnal Kesehatan Masyarakat Andalas, pp. 186 - 190, 2008.

[3] M Hisyam Hermawan and Nuri Kartini, "Analisa Kepuasan Pelayanan Kesehatan Dengan Pendekatan Importance Performance Analysis Dan Potential Gain In Customer Value's," Jurnal Improvement, pp. 31 - 39, 2016.

[4] Rudi Susilana and C Riyana, Pembelajaran: Hakikat, Pengembangan, Pemanfaatan, dan Penilaian.: Wacana Prima, 2008.

[5] Sapto Haryoko, "Efektivitas Pemanfaatan Media Audio Visual Sebagai Alternatif Optimalisasi Model Pembelajaran," Jurnal Edukasi Elektro Vol. 5 No. 1, pp. 1 - 10, 2009.

[6] Depkes RI, Pedoman Penyelenggaraan Rekam Medis Rumah Sakit di Indonesia. Jakarta: Depkes RI, 2006. 